\title{
The prevalence and causes of decreased visual acuity - a study based on vision screening conducted at Enukweni and Mzuzu Foundation Primary Schools, Malawi
}

\author{
This article was published in the following Dove Press journal: \\ Clinical Optometry \\ 19 December 2016 \\ Number of times this article has been viewed
}

\author{
Leaveson Thom' \\ Sanchia Jogessar ${ }^{1,2}$ \\ Sara L McGowan' \\ Fiona Lawless ${ }^{1,2}$ \\ 'Department of Optometry, \\ Mzuzu University, Mzuzu, Malawi; \\ ${ }^{2}$ Brienholden Vision Institute, Durban, \\ South Africa
}

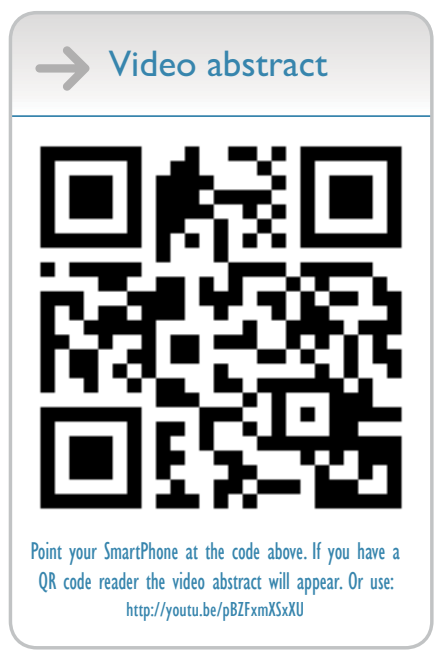

Correspondence: Sanchia Jogessar Optometrist, PO Box 28, Luxmi 3207, South Africa

Tel +27 7l 9378449

Email sjogessar@gmail.com

Sara L McGowan

Mzuzu University, Department of

Optometry, Private Bag 20I, Luwinga,

Mzuzu 2, Malawi

Tel +265998800737

Email saralynnmcg@gmail.com
Aim: To determine the prevalence and causes of decreased visual acuity (VA) among pupils recruited in two primary schools in Mzimba district, northern region of Malawi.

Materials and methods: The study was based on the vision screening which was conducted by optometrists at Enukweni and Mzuzu Foundation Primary Schools. The measurements during the screening included unaided distance monocular VA by using Low Vision Resource Center and Snellen chart, pinhole VA on any subject with VA of less than 6/6, refraction, pupil evaluations, ocular movements, ocular health, and shadow test.

Results: The prevalence of decreased VA was found to be low in school-going population (4\%, $\mathrm{n}=594)$. Even though Enukweni Primary School had few participants than Mzuzu Foundation Primary School, it had high prevalence of decreased VA $(5.8 \%, n=275)$ than Mzuzu Foundation Primary School $(1.8 \%, \mathrm{n}=319)$. The principal causes of decreased VA in this study were found to be amblyopia and uncorrected refractive errors, with myopia being the main cause than hyperopia. Conclusion: Based on the low prevalence of decreased VA due to myopia or hyperopia, it should not be concluded that refractive errors are an insignificant contributor to visual disability in Malawi. More vision screenings are required at a large scale on school-aged population to reflect the real situation on the ground. Cost-effective strategies are needed to address this easily treatable cause of vision impairment.

Keywords: vision screening, refractive errors, visual acuity, Enukweni, Mzuzu foundation

\section{Introduction}

Malawi has little information on decreased visual acuity (VA) in school-aged population. Other resources such as money and human resources are directed to other studies which mainly focus on HIV/AIDs and other pandemic diseases, thereby sidelining the other very important aspects of life such as vision. Uncorrected refractive error was found to be the major cause of reduced vision in school-aged population in Malawi. ${ }^{1}$ It was further concluded that the prevalence of diminished VA is similar to that in other surrounding countries such as Zambia, Tanzania, and some countries in sub-Saharan Africa. In all these countries, it was found that the prevalence of reduced vision due to uncorrected refractive errors is higher in urban population than in rural population.

However, in Kibaha District, Tanzania, it was found that the prevalence of decreased vision among school children was high and was increasing with age. It was learnt that 
the prevalence of low vision was statistically higher $(87 \%)$ among the children aged 12-17 years than among those of age 6-11 years $(13 \%)^{2}$

Strategies to address vision-related problems among school children in Malawi were started way back in 1997 by Save the Children fund. They introduced vision screening within the context of a comprehensive School Health and Nutrition program, aimed at addressing all key health and nutrition problems that prevent children from fully participating in school activities. Save the Children launched the program in 1999, initially reaching 101 schools in Mangochi, with an additional 70 schools in Balaka district added in 2004. Specialists trained four teachers per school to conduct initial vision screening of children. They tested all children in the first year to establish a baseline. In subsequent years, the teachers tested the following children: those entering the first grade, those who felt they had vision problem, and those identified by the teachers. Addressing the vision problem early ensured that children with impairments could fully participate in school activities.

A pediatric ophthalmologist's team involved in childhood blindness program has been operating in the southern region of Malawi since 2008 with support from both the government and various nongovernmental organizations. However, their services are not offered in the northern part of Malawi. Blantyre Institute for Community Ophthalmology is the only local nongovernmental organization which focuses on training volunteers and health surveillance assistants to identify blind and visually impaired children in the southern and central parts of Malawi and not in the northern region. In this paper, we report the prevalence and causes of decreased VA in school-aged population in northern Malawi.

\section{Methodology Research design}

In this study, we used a quantitative study design to determine the prevalence and causes of decreased VA in the regional school population.

\section{Setting}

The researcher used secondary data following the vision screening that was conducted at Enukweni and Mzuzu Foundation Primary Schools on 9th and 10th October 2012. These are in the rural and urban parts of Mzimba district, respectively. The study targeted learners from these two schools. Students irrespective of their age were included in this study. Teachers and any other participant who was not a pupil of these two primary schools were excluded.

\section{Sampling}

A convenient sampling was used to obtain the desired sample. This is a nonprobability sampling which included those subjects in the study who happened to be in the right place at the right time, entering the available subjects into the study until the desired sample size was reached. Purposive sampling was used as a type of nonprobability sampling in which the researcher selected those subjects who satisfied specified characteristics for a particular test. However, Enukweni and Mzuzu Foundation Primary Schools were chosen because vision screening was conducted in these two schools.

During the screening process, convenient sampling was used to select a number of boys and girls for participation in the study. A total of 594 subjects of age ranging between 4 and 18 years formed the sample which was available during vision screening. Of these, 275 subjects were from Enukweni Primary School, which represents $46.3 \%$ of the sample size. In this population, 139 were female, representing $50.6 \%$ of the sample size of Enukweni Primary School, and 133 subjects were males, giving a representation of $48.4 \%$.

However, 319 participants were chosen from Mzuzu Foundation Primary School by convenient sampling, and this represented $53.7 \%$ of the total population (594); 165 were females, representing $51.7 \%$ of the population, and 154 were males, representing $48.3 \%$ of the population.

This shows that out of the total sample of 594 subjects, 304 (51.2\%) were females while 287 (48.3\%) were males and three $(0.5 \%)$ were unknown. The population sample was from all the grades; that is, from Grade 1 to Grade 8 and their age ranged from 4 to 18 years.

\section{Data collection instrument}

Before data collection, a spreadsheet had been developed by the researcher to collect data from the Department of Optometry at Mzuzu University following vision screening which took place on 9th and 10th October 2012. The recording sheet included learner's profile, background, VA findings, external examination results, refraction findings, ocular health findings (both anterior and posterior segments), causes of the decreased VA, and finally, management given.

\section{Data collection}

Data was collected by the Department of Optometry from 9th to 12th April 2013. Before the vision screening, consent letters were obtained from the parents/guardians of these two selected primary school learners after obtaining approval for the research proposal from the Mzuzu University research and ethical committee and the Department of Optometry. 


\section{Measurement instruments}

A child examination card was used to collect data during the vision screening period. The screening team was composed of qualified optometrists and students from the Department of Optometry at Mzuzu University (Malawi). Testing during screening included the following procedures performed in the listed order:

\section{Monocular distance VA}

Due to the limited resources available within the optometry department, both Snellen charts and LogMAR charts were used. Test results were recorded in both Snellen equivalent and LogMAR values. The Low Vision Resource Center $\operatorname{logMAR}$ distance VA charts with tumbling-E optotypes or alphabetical optotype had the same sensitivity and repeatability. These charts were used at a distance of $4 \mathrm{~m}$ from the subjects to measure the distance VAs. Participants who used the Snellen charts were seated $6 \mathrm{~m}$ away from the chart.

\section{The VA}

The VA was examined unilaterally, with an occluder or the patient's palm covering the untested eye. Presenting VAs were recorded according to the line of the smallest optotypes the participant could see. VA was considered to be decreased if the eye with better vision was worse than $6 / 12$ at all ages.

\section{Pinhole VA}

Pinhole VA was taken to determine if the decreased VA was because of refractive error or due to pathology. Pinhole VAs were taken on the subjects with VAs worse than $6 / 6$, but it was considered significant when the decrease in VA was worse than 6/12. Participants were asked to occlude the nontested eye and use the tested eye to see through the pinhole of about $2 \mathrm{~mm}$ or less placed just close to the eye touching the eyelashes without squinting the eye. It is used to reduce the size of the blur circle in an ametropic eye. ${ }^{3}$ Vision will improve giving an indication of the final VA that will be obtained with corrective lenses. If no improvement occurs, the eye is considered to be amblyopic, or there is a pathological problem present.

\section{The ocular movements}

The ocular movements had been completed in all subjects to investigate the integrity of the extraocular muscles and their innervations. A penlight, pentorch, and ballpoint pen were used as fixation targets, and they were moved in eight meridians with the subjects' head kept still. Any limitation in movement indicated a fault in one of the extraocular muscles, so the subject was given a fail on the record card.

\section{Pupils}

Pupils were evaluated by swinging light from one eye to the other in a dark place while the subject was fixating a distant target (interesting diagrams were drawn on the blackboard as a target). Stimulation of the normal eye caused constriction of both pupils, whereas rapid stimulation of the affected eye led to a small dilatation and, in this case, the subject was given a fail on the record card. The subject was referred for further investigation.

\section{Cover test}

Cover test assessed the presence and type of heterophoria or strabismus. The subject fixated on a little diagram on the blackboard as a distant target and an occluder was placed over one eye and then removed while the examiner observed the other eye. If the open eye did not move, then the subject was considered not to have strabismus. If the open eye moved when the cover was placed in front of the covered eye, then strabismus was present, and the amount of the deviation was determined by using prism bars. Prisms of appropriate strength and base direction were placed on the eye while the cover was alternated from one eye to the other until the movements of the eye were neutral.

\section{Refraction}

Refraction was done to find and correct refractive errors in subjects who presented with reduced visual acuity of less than $6 / 6$ and if there is a pinhole assessment. It was considered significant if patients presented with a VA of 6/12 and less; and in such cases, the patient's eye was cyclopleged with two drops of $1 \%$ cyclopentolate to control accommodation. Cycloplegia was considered complete if the patient had full pupillary dilation of $6 \mathrm{~mm}$ or more with the absence of light reflex. Refraction was conducted on the same day after ascertaining that complete cycloplegia was present.

\section{Shadow test}

Shadow test assessed the approximate depth of the anterior chamber. It was carried out by placing the penlight or transilluminator on the temporal side of the eye at the level of the pupil and directing the beam of light horizontally toward the inner aspect of the eye. If the entire iris was illuminated, the subject was considered to have a deep anterior chamber. If the iris on the temporal side was illuminated and that on the nasal side was shadowed, then the subject had a shallow anterior chamber. 


\section{Ocular health}

A direct ophthalmoscope was used to assess the anterior segment and the posterior segment to determine the integrity of the eyelids, lashes, conjunctiva, cornea, and other refractive media, the disc ratio, macula, retinal vessels, and the peripheral retina. These results were recorded based on pass and fail criteria. So, if any abnormality was noticed, the patient would be referred for further assessment. Eyes of students who required further evaluation were dilated and assessed with a binocular indirect ophthalmoscope.

The researcher considered the following variables during data collection: age, grade, gender, unaided distance VA, pinhole VA, refraction results, ocular health findings, causes of VA reduction, and finally, management given to the subjects. All the examination record cards which were used during vision screening were kept safely at the Department of Optometry until the collection time by the researcher.

\section{Results of the study Demographics}

The study was designed to include all school-going pupils who attended the vision screening, and it was found that their age ranged from a minimum of 4 years to a maximum of 18 years. The age range of children from both schools was from 4 to 18 years. The mean age of children from Mzuzu Foundation Primary School was 8.63 years with the mode being 6 years, which is slightly higher than that of children from Enukweni Primary School where the mean age was 7.19 years with a mode of 7 years. It was noted that $85 \%$ of the participants in Mzuzu Foundation Primary School were between Grade 1 and Grade 4, while the remaining 15\% were dispersed between grade 5 and grade 8 . Similarly, $89 \%$ of the population at Enukweni Primary School consisted of grade 1 and grade 2 pupils, while the remaining $7.3 \%$ were dispersed from Grade 3 to Grade 8.

\section{Results of Mzuzu Foundation Primary School \\ UnaidedVA}

The participants had their VA taken monocularly, and the results were analyzed as such. Table 1 shows the results of both right and left eyes of children at Mzuzu Foundation Primary School. The numbers of males and females were recorded against their right and left eye VA, as seen in Table 1.

A total of 319 children participated from Mzuzu Foundation Primary School. Our results show that $73.4 \%$ (234 students) of the participants had a VA of $6 / 6$. Also, $51.3 \%$
Table I Distribution of VA among the male and female pupils at Mzuzu Foundation Primary School

\begin{tabular}{|c|c|c|c|c|}
\hline & Female & Male & Total & $\%$ \\
\hline \multicolumn{5}{|c|}{ VA - right eye } \\
\hline NLP & - & - & - & - \\
\hline $\mathrm{FC}$ at $3 \mathrm{~m}$ & 1 & 0 & I & 0.3 \\
\hline $6 / 60$ & - & - & - & - \\
\hline $6 / 36$ & 0 & I & 1 & 0.3 \\
\hline $6 / 15$ & - & - & - & - \\
\hline $6 / 12$ & 2 & I & 3 & 0.9 \\
\hline $6 / 9$ & 5 & 11 & 16 & 5 \\
\hline $6 / 7.5$ & 21 & 14 & 35 & $\mathrm{II}$ \\
\hline $6 / 6$ & 120 & 114 & 234 & 73.4 \\
\hline $6 / 5$ & 4 & 4 & 8 & 2.5 \\
\hline $6 / 4$ & 12 & 9 & 21 & 6.6 \\
\hline Total & 165 & 154 & 319 & 100 \\
\hline \multicolumn{5}{|c|}{ VA - left eye } \\
\hline NLP & 0 & I & 1 & 0.3 \\
\hline $\mathrm{FC}$ at $3 \mathrm{~m}$ & - & - & - & - \\
\hline $6 / 60$ & 1 & 0 & 1 & 0.3 \\
\hline $6 / 36$ & - & - & - & - \\
\hline $6 / 15$ & 0 & I & 1 & 0.3 \\
\hline $6 / 12$ & 2 & 1 & 3 & 0.3 \\
\hline $6 / 9$ & 7 & 9 & 16 & 5.0 \\
\hline $6 / 7.5$ & 20 & 18 & 38 & 11.9 \\
\hline $6 / 6$ & 117 & 118 & 228 & 71.5 \\
\hline $6 / 5$ & 5 & 3 & 8 & 2.5 \\
\hline $6 / 4$ & 13 & 10 & 23 & 7.2 \\
\hline Total & 165 & 161 & 319 & 100 \\
\hline
\end{tabular}

Abbreviations: $F C$ at $3 \mathrm{~m}$, finger counting at $3 \mathrm{~m}$; NLP, no light perception; VA, visual acuity.

(120) of the participants were female, while $48.7 \%$ (114) were male. Moreover, $6.6 \%$ (21) of the subjects had a VA of 6/4, of which 12 were female and nine subjects were male; $2.5 \%$ (8) of the population had a VA of $6 / 5$, which was distributed equally between male and female.

Our results show that $71.5 \%(n=319)$ of the participants had an unaided VA of $6 / 6$ in their left eye. Of these, 117 were female and 111 were male. Also, $7.2 \%$ of the population presented with an unaided VA of $6 / 4$ and $2.5 \%$ of the participants had an unaided VA of 6/5.

Of the 319 participants, $11 \%$ (35) presented with an unaided VA of 6/7.5, of which 21 were female and 14 were male. Also, 5\% (16) of the participants had a VA of 6/9, of which five were female and eleven were male. Decreased VA of $6 / 12$ was noticed in the right eye in $0.9 \%(n=319)$ of the population, of which $0.63 \%(n=319)$ consisted of girls and $0.27 \%(n=319)$ consisted of boys. Also, $0.3 \%(n=319)$ showed a VA of 6/36, which consisted of a male student. We noticed that one female had a VA less than 6/60 in her right eye. We were able to determine her acuity using the finger counting method at $3 \mathrm{~m}$. This contributed to $0.3 \%$ of the targeted population, as seen in Table 2. 
Table 2 Distribution of VA over the various age groups at Mzuzu Foundation Primary School

\begin{tabular}{|c|c|c|c|c|c|c|c|c|c|c|}
\hline $\begin{array}{l}\text { Age } \\
\text { (years) }\end{array}$ & $6 / 36$ & $6 / 24$ & $6 / 18$ & $6 / 15$ & $6 / 12$ & $6 / 9$ & $6 / 75$ & $6 / 6$ & $6 / 5$ & $6 / 4$ \\
\hline \multicolumn{11}{|c|}{ VA - right eye } \\
\hline 4 & 0 & 0 & 0 & 0 & I & 3 & 0 & 0 & I & 0 \\
\hline 5 & 0 & 0 & 0 & 0 & 0 & 1 & 0 & 4 & 0 & 0 \\
\hline 6 & 0 & 0 & 1 & 4 & 1 & 13 & 2 & 66 & 2 & 2 \\
\hline 7 & 0 & 0 & 0 & 3 & 0 & 20 & 7 & 75 & 5 & 3 \\
\hline 8 & 0 & 0 & 0 & 3 & 0 & 4 & 0 & 22 & 0 & 0 \\
\hline 9 & 0 & I & 0 & 1 & I & 0 & 0 & 6 & 0 & 1 \\
\hline 10 & 0 & 0 & 0 & 0 & 0 & I & 0 & 4 & 0 & 0 \\
\hline II & 0 & 0 & 0 & 0 & 0 & 1 & 0 & 3 & 0 & 0 \\
\hline 12 & 0 & 0 & 0 & 0 & 0 & 1 & 0 & 2 & 0 & I \\
\hline 13 & 0 & 0 & 0 & 0 & 0 & 0 & 0 & I & 0 & 0 \\
\hline 14 & 0 & 0 & 0 & 0 & 0 & 2 & 0 & 0 & 0 & 0 \\
\hline 15 & 0 & 0 & 0 & 0 & 0 & 0 & 0 & 1 & 0 & 0 \\
\hline 16 & 0 & 0 & 0 & 0 & 0 & I & 0 & 0 & 0 & 0 \\
\hline 17 & 1 & 0 & 0 & 0 & 0 & 0 & 0 & 0 & 0 & 0 \\
\hline 18 & 0 & 0 & 0 & 0 & 0 & 0 & 0 & I & 0 & 0 \\
\hline \multirow[t]{2}{*}{ Total } & 1 & 1 & 1 & 11 & 3 & 47 & 9 & 185 & 8 & 7 \\
\hline & $6 / 36$ & $6 / 24$ & $6 / 12$ & $6 / 9$ & $6 / 7.5$ & $6 / 6$ & $6 / 5$ & $6 / 4$ & & \\
\hline \multicolumn{11}{|c|}{ VA - left eye } \\
\hline 4 & 0 & 0 & 0 & 1 & 2 & 0 & I & 0 & & \\
\hline 5 & 0 & 0 & 0 & I & 1 & 3 & 0 & 0 & & \\
\hline 6 & 0 & 0 & 5 & 8 & 15 & 55 & 4 & 3 & & \\
\hline 7 & 0 & 0 & 3 & 13 & 16 & 74 & 4 & 3 & & \\
\hline 8 & 0 & 0 & 1 & 4 & 3 & 21 & 0 & 0 & & \\
\hline 9 & 0 & 0 & 2 & 1 & 2 & 3 & 0 & 1 & & \\
\hline 10 & 0 & 0 & 0 & I & 0 & 4 & 0 & 0 & & \\
\hline II & 0 & 0 & 0 & 2 & 0 & 2 & 0 & 0 & & \\
\hline 12 & 0 & 0 & 0 & I & 1 & 1 & 0 & 1 & & \\
\hline 13 & 0 & 0 & 0 & 0 & 0 & 1 & 0 & 0 & & \\
\hline 14 & I & 0 & 0 & 0 & 2 & 0 & 0 & 0 & & \\
\hline 15 & 0 & 0 & 0 & 0 & 0 & 1 & 0 & 0 & & \\
\hline 16 & 0 & 0 & 0 & I & 0 & 0 & 0 & 0 & & \\
\hline 17 & 0 & 1 & 0 & 0 & 0 & 0 & 0 & 0 & & \\
\hline 18 & 0 & 0 & 0 & I & 0 & 0 & 0 & 0 & & \\
\hline Total & 1 & 1 & 11 & 34 & 42 & 165 & 9 & 8 & & \\
\hline
\end{tabular}

Abbreviations: $\mathrm{FC}$ at $3 \mathrm{~m}$, finger counting at $3 \mathrm{~m}$; $\mathrm{VA}$, visual acuity.

Analysis of the left eye showed that $11.9 \%$ of the population, comprising 20 females and 18 males, had an acuity of 6/7.5. Our results show that $5 \%$ of the population at Mzuzu Foundation Primary School had a VA of 6/9, which consisted of seven females and nine males. A decrease in VA of 6/12 was noticed in the left eye of $0.9 \%(n=319)$ of the participants. In this population, there were two female and one male. VA reduction of $6 / 15$ was present in one male, which accounted for $0.3 \%(n=319)$ of the population. One female had a VA of $6 / 60$ in the left eye, representing a VA reduction of $0.3 \%$ $(n=319)$; also, a young male had no light perception in this left eye.

Comparatively, we noted that the left eye had a lower VA $(1.8 \%)$ than the right eye among the students at Mzuzu Foundation Primary School, as seen in Table 2. The prevalence of VA reduction was found to be similar in both girls and boys, and it was $0.9 \%(\mathrm{n}=319)$ in each case.

\section{Pinhole VA}

We observed that only $0.63 \%(n=319)$ of the participants at Mzuzu Foundation Primary School had improved vision after a pinhole assessment in their right eye. We noted that in $0.94 \%(n=319)$ of the study population, vision did not improve with the pinhole in their right eye. However, 98.4\% of the participants $(n=319)$ needed no pinhole because they had VA within the normal range (6/6-6/9), according to this study. We noted that $1.9 \%(\mathrm{n}=319)$ of the participants at Mzuzu foundation had reduced vision in their left eye, which required a pinhole assessment. One male had his vision restored to $6 / 6$. Our results show that $1.5 \%$ of the population had no improvement with pinhole (NIPH), which indicated that refractive correction would not be successful. Of these, three were female and two were male. Our results show that $98.1 \%$ needed no pinhole in their left eye. The results are presented in Table 3.

\section{Results of Enukweni Primary School UnaidedVA}

Analysis of the right eye showed that $68.4 \%$ of the student population had a VA of 6/6, which consisted of 96 male students and 90 female students. Also, $2.9 \%$ of the population presented with a VA of $6 / 5$. This consisted of seven females and one male. We observed that $2.6 \%(\mathrm{n}=272)$ of the population presented with an unaided VA of 6.4, which included three female students and one male.

Analysis of the left eye of students at Enukweni Primary School showed that $60 \%(\mathrm{n}=272)$ of the population possessed an acuity of 6/6, of which 77 participants were female and

Table 3 Distribution of pinhole acuity at Mzuzu Foundation Primary School

\begin{tabular}{llll}
\hline Pinhole status & Female & Male & Total \\
\hline Right eye & 2 & 1 & 3 \\
NIPH & 0 & 0 & 0 \\
IPH to 6/6 & $\mathrm{I}$ & $\mathrm{I}$ & 2 \\
IPH to 6/7.5 & 162 & 152 & 314 \\
No pinhole required & 165 & 154 & 319 \\
Total & & & \\
Left eye & 3 & 2 & 5 \\
NIPH & 0 & 1 & 1 \\
IPH to 6/6 & 0 & 0 & 0 \\
IPH to 6/7.5 & 162 & 151 & 313 \\
No pinhole required & 165 & 154 & 319 \\
Total & Ab
\end{tabular}

Abbreviations: IPH to 6/6, improvement with pinhole to $6 / 6$; IPH to $6 / 7.5$, improvement with pinhole to $6 / 7.5$; NIPH, no improvement with pinhole. 
89 were male. We observed that $2.9 \%$ of the population possessed an unaided VA of $6 / 4$, while $3.3 \%$ represented a VA of 6/5, as shown in Table 4.

Further examination of VA less than $6 / 6$ in the right eye showed that $3.3 \%$ of the student population exhibited an unaided VA of 6/7.5, of which 25 participants were female and 22 were male. We observed that $17.3 \%$ of the student population presented with an acuity of 6/9 in the right eye. Our results revealed that $4 \%(n=272)$ of the population had a VA of $6 / 12$, which consisted of seven female and four male students.

Additional examination of VA less than $6 / 6$ in the left eye showed that reduced VAs of $6 / 15,6 / 18,6 / 24$, and $6 / 35$ were detected in $0.4 \%$ of the population in each case. We noted that the number of patients who had a VA of 6/12 in the left eye consisted of seven females and four males, and constituted $4.0 \%$ of the total number of patients seen.

Our results show a prevalence of $15.4 \%$ for VA of $6 / 7.5$ in the left eye, of which 27 were female and 15 were male participants. A total of 34 students presented with a VA of $6 / 9$, constituting $12.5 \%(n=275)$ to the total number of participants. Analysis of results indicated that $4 \%$ of the total number of students presented with a VA of $6 / 12$. This figure is identical to the number of students who had a VA of $6 / 12$ in their right eye, of which six were female and five were male.

Table 4 Distribution of distance VA among the student population at Enukweni Primary School

\begin{tabular}{lllll}
\hline VA & Female & Male & Total & $\%$ \\
\hline VA - right eye & & & & \\
$6 / 36$ & 0 & 1 & 1 & 0.4 \\
$6 / 24$ & 0 & 1 & 1 & 0.4 \\
$6 / 18$ & 1 & 0 & 1 & 0.4 \\
$6 / 15$ & 0 & 1 & 1 & 0.4 \\
$6 / 12$ & 7 & 4 & 11 & 4.0 \\
$6 / 9$ & 25 & 22 & 47 & 17.3 \\
$6 / 7.5$ & 5 & 4 & 9 & 3.3 \\
$6 / 6$ & 90 & 96 & 186 & 68.4 \\
$6 / 5$ & 7 & 1 & 8 & 2.9 \\
$6 / 4$ & 3 & 4 & 7 & 2.6 \\
Total & 138 & 134 & 272 & 100 \\
VA - left eye & & & & \\
$6 / 36$ & 0 & 1 & 1 & 0.4 \\
$6 / 24$ & 0 & 1 & 1 & 0.4 \\
$6 / 18$ & & & & \\
$6 / 15$ & & & & \\
$6 / 12$ & 6 & 5 & 11 & 4.0 \\
$6 / 9$ & 19 & 15 & 34 & 12.5 \\
$6 / 7.5$ & 27 & 15 & 42 & 15.4 \\
$6 / 6$ & 77 & 89 & 166 & 61.0 \\
$6 / 5$ & 5 & 4 & 9 & 3.3 \\
$6 / 4$ & 4 & 4 & 8 & 2.9 \\
Total & 138 & 134 & 272 & 100 \\
\hline A66revation & & & &
\end{tabular}

Abbreviation: VA, visual acuity.
Two male students presented with a VA of $6 / 36$, constituting $0.8 \%$ of the participants.

Table 5 shows the distance VA of the right eye against the age of the participants from Enukweni Primary School. It is seen that most of the participants were in the age range of 4-9 years. We noted that $4 \%(n=272)$ of the participants with a decreased VA of 6/12 were in the age range of 6-9 years, with more participants being of age 6 years. Reduced VAs of $6 / 15,6 / 18,6 / 24$, and $6 / 35$ had a prevalence of $0.4 \%$ in each case, and the participants were $6,9,14$, and 17 years old, respectively.

We observed that $68.4 \%(n=272)$ of the population presented with a VA of $6 / 6$ in the right eye and the majority of this population fell in the age range of 6-9 years. Considering

Table 5 Distribution of VA over the various age groups at Enukweni Primary School

\begin{tabular}{|c|c|c|c|c|c|c|c|c|c|c|}
\hline $\begin{array}{l}\text { Age } \\
\text { (years) }\end{array}$ & $6 / 36$ & $6 / 24$ & $6 / 18$ & $6 / 15$ & $6 / 12$ & $6 / 9$ & $6 / 75$ & $6 / 6$ & $6 / 5$ & $6 / 4$ \\
\hline \multicolumn{11}{|c|}{ VA - right eye } \\
\hline 4 & 0 & 0 & 0 & 0 & 1 & 3 & 0 & 0 & I & 0 \\
\hline 5 & 0 & 0 & 0 & 0 & 0 & I & 0 & 4 & 0 & 0 \\
\hline 6 & 0 & 0 & 1 & 4 & 1 & 13 & 2 & 66 & 2 & 2 \\
\hline 7 & 0 & 0 & 0 & 3 & 0 & 20 & 7 & 75 & 5 & 3 \\
\hline 8 & 0 & 0 & 0 & 3 & 0 & 4 & 0 & 22 & 0 & 0 \\
\hline 9 & 0 & I & 0 & 1 & 1 & 0 & 0 & 6 & 0 & I \\
\hline 10 & 0 & 0 & 0 & 0 & 0 & I & 0 & 4 & 0 & 0 \\
\hline 11 & 0 & 0 & 0 & 0 & 0 & I & 0 & 3 & 0 & 0 \\
\hline 12 & 0 & 0 & 0 & 0 & 0 & I & 0 & 2 & 0 & I \\
\hline 13 & 0 & 0 & 0 & 0 & 0 & 0 & 0 & I & 0 & 0 \\
\hline 14 & 0 & 0 & 0 & 0 & 0 & 2 & 0 & 0 & 0 & 0 \\
\hline 15 & 0 & 0 & 0 & 0 & 0 & 0 & 0 & I & 0 & 0 \\
\hline 16 & 0 & 0 & 0 & 0 & 0 & I & 0 & 0 & 0 & 0 \\
\hline 17 & I & 0 & 0 & 0 & 0 & 0 & 0 & 0 & 0 & 0 \\
\hline 18 & 0 & 0 & 0 & 0 & 0 & 0 & 0 & I & 0 & 0 \\
\hline \multirow[t]{2}{*}{ Total } & I & I & I & 11 & 3 & 47 & 9 & 185 & 8 & 7 \\
\hline & $6 / 36$ & $6 / 24$ & $6 / 12$ & $6 / 9$ & $6 / 7.5$ & $6 / 6$ & $6 / 5$ & $6 / 4$ & & \\
\hline \multicolumn{11}{|c|}{ VA - left eye } \\
\hline 4 & 0 & 0 & 0 & I & 2 & 0 & 1 & 0 & & \\
\hline 5 & 0 & 0 & 0 & I & I & 3 & 0 & 0 & & \\
\hline 6 & 0 & 0 & 5 & 8 & 15 & 55 & 4 & 3 & & \\
\hline 7 & 0 & 0 & 3 & 13 & 16 & 74 & 4 & 3 & & \\
\hline 8 & 0 & 0 & 1 & 4 & 3 & 21 & 0 & 0 & & \\
\hline 9 & 0 & 0 & 2 & 1 & 2 & 3 & 0 & I & & \\
\hline 10 & 0 & 0 & 0 & I & 0 & 4 & 0 & 0 & & \\
\hline 11 & 0 & 0 & 0 & 2 & 0 & 2 & 0 & 0 & & \\
\hline 12 & 0 & 0 & 0 & I & I & I & 0 & I & & \\
\hline 13 & 0 & 0 & 0 & 0 & 0 & I & 0 & 0 & & \\
\hline 14 & I & 0 & 0 & 0 & 2 & 0 & 0 & 0 & & \\
\hline 15 & 0 & 0 & 0 & 0 & 0 & I & 0 & 0 & & \\
\hline 16 & 0 & 0 & 0 & I & 0 & 0 & 0 & 0 & & \\
\hline 17 & 0 & I & 0 & 0 & 0 & 0 & 0 & 0 & & \\
\hline 18 & 0 & 0 & 0 & I & 0 & 0 & 0 & 0 & & \\
\hline Total & I & I & II & 34 & 42 & 165 & 9 & 8 & & \\
\hline
\end{tabular}

Abbreviation: VA, visual acuity. 
the right eye, VAs of $6 / 4,6 / 5,6 / 7.5$, and $6 / 9$ originated from the age range of $6-8$ years, with a few subjects being in the age range of $10-18$ years.

We noted that $61 \%(n=272)$ of the participants had a VA of 6/6 in the left eye, of which majority belonged to the 6-8-year-old age range and the remainder were between 9 and 15 years of age. Most children who had VAs of $6 / 4,6 / 5$, $6 / 7.5$, and 6/9 were between 6 and 7 years of age.

The prevalence of decreased VA of 6/12 was found to be $4.0 \%(n=275)$ in the left eye at Enukweni Primary School. This was found in the age range of 6-9 years, with a high prevalence observed in students of age 6 years. There was one participant with VA of $6 / 24$ and another with VA of $6 / 36$ at 17 and 14 years, respectively. The total prevalence of these two was $0.7 \%$.

\section{VA with pinhole}

Pinhole VA was measured in those participants who did not have a vision of $6 / 6$, in order to establish the gross presence of pathological causes for reduced VA. In this study, pinhole VA was considered to be very significant to those who presented with unaided VA of $6 / 12$ or worse in one eye. Table 6 shows the results of the pinhole VA against the age of the participants at Enukweni Primary School.

It is seen from the table that among 5.8\% $(n=275)$ of the participants with reduced vision in their right eye, $4.0 \%$ $(n=275)$ did not improve with the pinhole (NIPH), and of this, $2.9 \%$ were female. However, $1.5 \%$ of the population had improved VA of $6 / 6$, which consisted of all male students. One female student had her vision improved to $6 / 9$ in her right eye. We noted that $93 \%$ of the students at Enukweni Primary School did not require a pinhole acuity assessment for their right eye. Concerning the left eye, our

Table 6 Distribution of pinhole acuity at Enukweni Primary School

\begin{tabular}{llll}
\hline Pinhole status & Female & Male & Total \\
\hline Right eye & 8 & 3 & \\
NIPH & 0 & 4 & $1 \mathrm{I}$ \\
IPH to 6/6 & $\mathrm{I}$ & 0 & 4 \\
IPH to 6/9 & 129 & 127 & $\mathrm{I}$ \\
No pinhole required & 138 & 134 & 272 \\
Total & & & \\
Left eye & 6 & 3 & 9 \\
NIPH & 0 & 4 & 4 \\
IPH to 6/6 & 0 & 0 & 0 \\
IPH to 6/9 & 132 & 127 & 259 \\
No pinhole required & 138 & 134 & 272 \\
Total &
\end{tabular}

Abbreviations: IPH to $6 / 6$, improvement with pinhole to $6 / 6 ; \mathrm{IPH}$ to $6 / 9$, improvement with pinhole to 6/9; NIPH, no improvement with pinhole. results show that nine students could not improve their VA in their left eye with a pinhole assessment. Four participants had improved vision with pinhole up to $6 / 6$, which were all male. We noted that $93.5 \%$ of the student population at Enukweni Primary School did not require a pinhole VA assessment.

\section{Causes of decreased VA at Mzuzu Foundation Primary School}

Of the six (1.9\%) children with reduced VA at Mzuzu Foundation Primary School, one $(0.3 \%)$ had decreased vision in the right eye only, two $(0.63 \%)$ had decreased vision in the left eye only, and three $(0.94 \%)$ had decreased VA in both eyes. We learned that the primary cause of VA reduction in both eyes was amblyopia, with a higher prevalence in the right eye than in the left. This was followed by uncorrected refractive errors and, in the case of the single female student with NIPH assessment in her right eye, suspected macular dystrophy. We were able to analyze the fundus by performing a dilated fundus exam at the outreach site.

\section{Causes of decreased VA at Enukweni Primary School}

Out of 16 (5.82\%), children with reduced VA at Enukweni Primary School, four (1.5\%) had poor vision in the right eye only, one $(0.4 \%)$ had poor vision in the left eye only, while eleven $(4.0 \%)$ had poor vision in both eyes.

Refractive errors, amblyopia and pathologies were found to be the causes ofVA reduction at Enukweni Primary School during the vision screening. Ten (3.64\%) participants had VA decrease due to amblyopia; seven of them were female students and three were male. Uncorrected refractive errors caused VA reduction in three $(1.1 \%)$ boys only and the other three $(1.1 \%)$ participants had a decrease in VA in their right eye due to pathological conditions. Retinal disorder, quiescent inflammation, and a component of retinal detachment were observed in the right eye of a 9-year-old boy and iridocorneal adhesion was suspected in a 9-year-old girl.

We noted similar results in the left eye, with the majority of the visual decrease being caused by amblyopia, followed by uncorrected refractive errors and a pathological condition which was also observed in the right eye of the participant. We noted a retinal disorder, quiescent inflammation, and retinal detachment components in a 9-year-old boy, which were also found in his right eye. We found that the causes of decreased VA in Mzuzu Foundation Primary School and Enukweni Primary School were: amblyopia, uncorrected 
refractive errors, and pathologies. All the participants found to have pathological problems in the vision outreach clinic were referred to Mzuzu Central Hospital for further ocular assessment.

Refractive error was found in $0.6 \%(n=319)$ participants at Mzuzu Foundation Primary School. In this case, there was a girl and a boy of 6 and 9 years of age, who were from Grade 2 and 3, respectively. Equal distribution of hypermetropia and myopia was noticed, in which a girl had a cyclo-prescription of +1.50 DS in her right eye only and a boy had -5.75 DS in the right eye and $-3.50 \mathrm{DS}$ in the left eye. Spectacles were prescribed to the hyperopic patient, while the myopic patient had his spectacles ordered.

At Enukweni Primary School, refractive errors were noticed in $1.5 \%(\mathrm{n}=272)$ of the participants. Of this population, $75 \%$ were male students and $25 \%$ were females. Astigmatism was seen in two students who were 9 and 14 years old, respectively. Spectacles were ordered in both cases.

Simple myopia of -1.00 and -2.00 DS was noticed in two boys, and they were given glasses on the same day of vision screening. This low prevalence of vision-impairing refractive error is consistent with the findings of surveys from other developing countries in both urban and rural settings.

Though the problems existed, as shown above, none of the participants had prescriptive spectacles for either distance or near vision during the screening period.

Our results show the major suspected causes of decreased VA in the right eye, and it was found that $60 \%$ of the visual decrease was caused by amblyopia and the remaining $40 \%$ was from refractive errors. In the left eye, amblyopia and refractive errors contributed similar visual decrease. They produced $40 \%$ in each case, while the remaining $20 \%$ was from pathologies (corneal scar in left eye). Therefore, amblyopia and uncorrected refractive errors were found to remain as the leading causes of reduced VA in a school-going population.

\section{Discussion and conclusion}

The study enrolled 591 school children totally, of which 319 (54\%) were from Mzuzu Foundation Primary School and 272 (46\%) from Enukweni Primary School. The sample consisted of 165 and 139 girls from Mzuzu foundation and Enukweni Primary School, respectively. Also, there were 154 and 136 boys from Mzuzu foundation and Enukweni Primary School, respectively.

Normal monocular distance VA (6/9 or better) of the right eye was found in 314 and 256 participants at Mzuzu foundation and Enukweni Primary School s, respectively. This represented $96 \%(n=594)$ of the normal participants in this study. Therefore, the overall prevalence of decreased VA in the right eye was 4\%. Of this, $67.3 \%$ (16) participants were from Enukweni Primary School and 32.7\% (5) were from Mzuzu Foundation Primary School. Though not significantly important, there were differences in the prevalence of VA decrease in the left eye as compared with that of the right eye, but the reasons for the differences are not discussed in this study. Also, 313 and 259 participants showed normal VA (6/9 or better) in the left eye at Mzuzu Foundation Primary School and Enukweni Primary School, respectively.

This represented $96.3 \%(n=591)$ of the normal participants and a prevalence of $3.7 \%$ of decreased VA in the left eye. Of this, 13 (68.4\%) were from Enukweni Primary School and six (31.6\%) were from Mzuzu Foundation Primary School. Age and gender of the participants were compared to their VA at a distance and majority of the VA decrease was found in children of age ranging 6-9 years. We found out that there were no significant differences in VA according to the gender of the participants; however, there was a higher prevalence of decreased VA in girls than in boys. This is probably due to the larger female population enrolled in this study. This is similar to what was found in USA in 2004 and in Nigeria in $2016^{4}$ where VA reduction had a lower prevalence in males compared to females and higher prevalence was found among first grade pupils compared to fourth grade pupils. ${ }^{5}$ Kovin and Leasher reported that visual impairment has a high prevalence in women globally. ${ }^{6}$ It is possible that uncorrected refractive error in young female patients is related to the higher prevalence of visual impairment in women.

Even though the sample size of Enukweni Primary School was less than that of Mzuzu Foundation Primary School, the prevalence of decreased monocular VA was higher at Enukweni Primary School located in a rural part of Mzimba district than at Mzuzu Foundation Primary School located in an urban part of the district. This is probably due to the lack of proper primary eye care services to these rural students. Similar results were reported by Salomao et al, ${ }^{7}$ where the prevalence of decreased vision was small in children from low- and middle-income areas than those in high-income areas, with poverty being an exacerbating factor suggested in their study.

With uncorrected vision, $5.8 \%(n=275)$ of the children at Enukweni Primary School had a VA of 6/12 or worse in the right eye. Over half (62\%) of this decrease was attributable to amblyopia, the refractive error was implicated in $19 \%$ of children, and pathologies (retinal disorders and corneal 
opacity) were the principal cause in $19 \%$ as well. The prevalence of decreased VA in the left eye was $4.7 \%(n=275)$, and causes of this decrease were similar to those found in the right eye. It is learnt that $67 \%$ of this VA decrease was caused by amblyopia, while $25 \%$ and $8 \%$ of this reduction were caused by refractive errors and retinal disorders, respectively. The study shows findings similar to those found as the leading causes of VA decrease. According to VIP studies, Phase II, ${ }^{8}$ refractive error, amblyopia, retinal disorders, corneal opacity, and other ocular diseases were the main causes of decreased VA, with refractive errors found in about $63.6 \%$ of the schoolaged population. In the present study, amblyopia seems to dominate as a major cause of VA decrease due to poor visual experience. This is due to the lack of eye care services in rural areas which leads to poor vision development in these children. Similar findings were also reported in Osogbo, Nigeria, which showed that, while a high percentage of children did not have reduced VA, the leading causes of reduced VA were refractive errors, amblyopia, and pathologies. ${ }^{4}$

However, at Mzuzu Foundation Primary School, the prevalence of decreased VA was $1.6 \%(n=319)$ in the right eye and $1.8 \%(n=319)$ in the left eye, which was different from that of Enukweni Primary School. Wedner et $\mathrm{al}^{9}$ conducted a similar study in Mwanza region in Tanzania and found that $1.7 \%$ had poor eyesight, and refractive error was found to be the primary cause of vision reduction. This also shows that the occurrence of reduced VA in school-aged population is low, and mostly it is caused by refractive errors and amblyopia. Another study which was completed in South Africa by Naidoo et $\mathrm{al}^{10}$ reported that $1.4 \%$ children had uncorrected vision of 20/40 or worse in the better eye, with five children who were blind in both eyes, which shows that the prevalence of decreased VA is low in school children.

This low prevalence of reduced vision is consistent with the findings from surveys in the urban and rural settings of other developing countries. ${ }^{3,4,10-12}$ Amblyopia and uncorrected refractive errors remain the major causes of visual decrease in school-aged population. Taking into consideration that a significant population of children with refractive errors is learning without refractive correction, the low prevalence of decreased VA in these primary schools should not generalize that there is low prevalence of refractive errors in Malawi. More vision screenings are required on a large scale to address this avoidable cause of blindness in Malawi. Because decreased VA can have a great negative effect on the social and educational development in a child's life, effective strategies on vision screening programs should be put in place to eliminate the easily treatable causes of visual decrease, such as refractive errors. ${ }^{13-15}$ It is only through early screenings that development of amblyopia can be avoided in school-aged population.

\section{Acknowledgments}

We wish to acknowledge the services of Brienholden Vision Institute, Canadian Vision Care, Malawi School of Optometry, Mzuzu University, the Ministry of Education, and the optometry students from class of 2013 who supported us during the vision screening period.

\section{Disclosure}

The authors report no conflicts of interest in this work.

\section{References}

1. Sherwin JC, Lewallen S, Courtright P. Blindness and visual Impairment due to uncorrected refractive error in sub-Saharan Africa. review of recent population-based studies. Br J Ophthalmol. 2012:96(7): 927-930.

2. Kingo AU, Ndawi BT. Prevalence and causes of low vision among school children in Kibaha District, Tanzania. Tanzan J Health Res. 2009: 11(3):111-115.

3. Millodot M. Dictionary of Optometry and Visual Science. 7th ed. Oxford, UK: Butterworth-Heinemann; 2009.

4. Isawumi M, Aboola S, BimbomA. Peadiatric refractive errors in an eye clinic in Osogbo, Nigeria. Ethiop J Health Sci. 2016:26(2): 147-158.

5. Gianini RJ, Masi Ed, Coelho EC, Oréfice FR, Moraes RA. Prevalence of low visual acuity in public school's students from Brazil. Rev Saude Publica. 2004:38(2):201-208.

6. Mohammed K, Mohammadreza G, Zeidi IM. Prevalence of refractive errors in primary school children (7-15 yrs) of Qazvin city. Eur J Sci Res. 2009:28(2):174-185.

7. Salomao SR, Cinoto RW, Berezovsky A, et al. Prevalence and causes of visual impairment in low-middle income school children in Sao Paulo, Brazil. Invest Ophthalmol Vis Sci. 2008;49(10):4308-4313.

8. Dobson V, Maguire M, Orel-Bixler D, Quinn G, Ying GS; Vision in Preschoolers (VIP) Study Group. Visual acuity results in school-aged children and adults: Lea symbols chart versus Bailey-Lovie chart. Optom Vis Sci. 2003;80(9):650-654.

9. Wedner SH, Ross DA, Balira R, Kaji L, Foster A. Prevalence of eye diseases in primary school children in a rural area of Tanzania. $\mathrm{Br} J$ ophthalmol. 2000;84(11):1291-1297.

10. Uzma N, Kumar BS, Khaja Mohinuddin Salar BM, Zafar MA, Reddy VD. A comparative clinical Survey of prevalence of refractive errors and eye diseases in urban and rural school children. Can J Ophthalmol. 2009;44(3):328-333.

11. Diran M, Zhou B, Hornbeak D, et al.The prevalence and causes of decreased visual acuity in Singaporean Chinese Preschoolers. $\mathrm{Br} J$ Ophthalmol. 2010;94(12):1561-1565.

12. Padhye AS, Khandekar R, Dharmadhikari S, Dole K, Gogate P, Deshpande M. Prevalence of uncorrected refractive eand other eye problems among Urban and Rural school children. Middle East Afr J Ophthalmol. 2009;16(2):69-74.

13. Naido KS, Raghunandan A, Mashige KP, Govender P, Holden BA, Pokharel GP, Ellwein LB. Refractive error and visual impairment in African children in South Africa. Invest Ophthalmol Vis Sci. 2003;44(9): 3764-3770.

14. Naidoo KS, Leasher J, Bourne RR, et al. Global vision impairment and blindness due to uncorrected refractive error, 1990-2010. Optom Vis Sci. 2016:93(3):227-234.

15. Solange R, Rafael W, Adriana B, et al. Prevalence and auses of visual impairment in low-middle income school children in São Paulo, Brazil. Invest Ophthalmol Vis Sci. 2008;49(10):4308-4313. 


\section{Publish your work in this journal}

Clinical Optometry is an international, peer-reviewed, open access journal publishing original research, basic science, clinical and epidemiological studies, reviews and evaluations on clinical optometry. All aspects of patient care are addressed within the journal as well as the practice of optometry including economic and business analyses. Basic and clinical

Submit your manuscript here: https://www.dovepress.com/clinical-optometry-journal research papers are published that cover all aspects of optics, refraction and its application to the theory and practice of optometry. The manuscript management system is completely online and includes a very quick and fair peer-review system, which is all easy to use. Visit http://www.dovepress. com/testimonials.php to read real quotes from published authors. 